\title{
Farm Safety Practices: Reports from Rural Youth in North Carolina
}

\author{
Paula E. Faulkner, PhD \\ John Owens, MS \\ Amber Brown, Graduate Student \\ North Carolina Agricultural and Technical State University, USA
}

Doi: 10.19044/esj.2018.v14n27p1 URL:http://dx.doi.org/10.19044/esj.2018.v14n27p1

\begin{abstract}
Farms require an extensive labor force to meet production demands. In rural areas, the demand is greater, and farm operators must often rely on family members, including youth, who face unique risks due to farming practices. This quantitative study examined rural high school agricultural education programs in which students participate in family farming operations. The purpose of this study was to determine rural youths' knowledge about farm safety and health hazards. Participants completed class activities related to farm safety and participated in farm safety demonstrations. It was found that most students reported being slightly knowledgeable about and practiced safety farming practices. It was concluded that, while most students reported having knowledge of farm safety practices, they fail to always practice them. The researchers recommend youth and at a younger age of diverse backgrounds received more farm safety practice initiatives in order to reduce the number of injuries and fatalities.
\end{abstract}

Keywords: Rural Youth, Rural, Farm Safety, North Carolina, Agriculture

\section{Introduction}

Agriculture is North Carolina's top industry generating more than $\$ 84$ billion in revenue yearly (S. Troxler, personal communication, July 14, 2016). According to the 2017 Census of Agriculture, there are approximately 47,800 farms in North Carolina, where approximately $88 \%$ are considered small (gross sales less than $\$ 250,000$ ), with an average size of 169 acres. Principal farm operators (farming and others), include: 50,218, which includes 43,765 $(87 \%)$ males and $6453(13 \%)$ females. Based on race/ethnicity, there are majority White, followed by (2.9\%) African-American, (1.2\%) American Indian, (1.1\%) Hispanic, and (.4\%) Asian farmers (USDA National 
Agricultural Statistics Service, 2017). Farm operations produce an array of items, such as cotton, turkeys, broilers and Christmas trees. North Carolina farms require an extensive labor force to meet production demands. Many large -farm operators have hired Hispanic migrant workers to fulfill this need. However, in rural areas, many small-farm operators must rely on family members or hire adolescents for seasonal work, resulting in more than 1.47 million youth under the age of 20 working or living on farms in the United States (OSHA, 2014).

For many rural youth, farming is not only their family's livelihood, but it is also their way of life. Many youth complete farming tasks (i.e. milking, feeding) before attending school. For these youth, their evenings, weekends and/or summers are reserved for farming. The home and worksite are the same location for most farmers, which places family members at greater exposure to hazards associated with machinery, tools, and chemicals (NIOSH, 2014).

Agricultural work is physically demanding and remains one of the most accident-prone industries in the United States. Youth have one of the highest injury rates in agriculture, compared to other occupations. Approximately 15,900 youth under the age of 20 who lived on, worked on, or visited a farm operation in 2009 were injured (USDA, 2012). Youth working on farms face unique risks that are not present for young workers in other occupations; some of these risks include machinery, large animals, electrical hazards, chemical hazards and excessive noise (Hard \& Myers, 2008). Hand and Myers reported in their study that, from 1992 to 2000, there were 310 work-related deaths to youth younger than age 20 in the agricultureproduction sector. This compares to 1,958 total fatalities for workers less than 20 years of age in all occupations for the same time period (Hard \& Myers, 2008).

\section{Purpose and Objective of the Study}

The main purpose of this quantitative study was to determine rural youth knowledge of farming safety and health hazards. The research question used to guide this study was:

1- What knowledge was acquired by rural youth about farm safety practices after participating in a farm safety demonstration?

\section{Method}

The study was conducted fall 2015 to spring 2016. The project time frame was based on the participants' school-system academic calendar. The participants in this study were fifty-five students enrolled in vocational agricultural education programs in two high schools located in Western North Carolina. The researcher worked with Cooperative Extension Service (CES) 
educators from Alleghany County and high school teachers from the two vocational agricultural education programs to recruit and select students for the study. Approval from the researcher's University Internal Review Board (IRB) provided approval for the study to be conducted (Protocol\# 15-0214). The CES educators and teachers informed students about the study's purpose. Students were required to obtain parental consent in order to participate during the study. A questionnaire was administered to all students (100\% response rate) who returned parent consent forms. Descriptive statistics (frequency, percentages) were used to analyze the data using the Statistical Package for the Social Sciences (SPSS), version, 23.

\section{Farm Safety Field Day}

The Farm Safety Field Day was held at the Upper Mountain Research Station in Laurel Springs, North Carolina. Collaborators during the event included: personnel from both Ashe and Grayson County Cooperative Extension, the North Carolina Farm Bureau, the North Carolina Farm Credit, North Carolina Agromedicine Institute, the North Carolina AgrAbility Program, the North Carolina Farm Worker Health Program and several local farm suppliers.

The Farm Safety Field Day began with student registration, small group assignments, an informational session to cover the daily events, and nine, 15-minute farm-safety demonstrations related to tractor rollover, how to operate Power Take-Offs ( PTOs), All-terrain vehicles ( ATVs), chainsaws, and proper use of pesticides. The tractor rollover demonstration was conducted with Rollover Protection Structure (ROPS) and an attached seatbelt on the mannequin, and again without ROPS and no attached seatbelt.

\section{Survey Instrument}

The researchers developed the questionnaire in three sections. Section one included 18 true/false items that measured participant's farm safety knowledge. Section two included questions to gather background information about the participants, such as grade level, gender, farm topography and number of days lived, visited or worked on a farm. Section three consisted of 11, 4-point, Likert-style items (1=Always, 2=Sometimes, $3=$ Never, and $4=$ Unsure) related to the participants' farm safety practices. All research documents were translated from English into Spanish for those participants who self-reported as English as Second Language (ESL).

\section{Results}

The questionnaire consisted of 18 , true/false, farm-safety items in addition to items related to farm-safety practices. Table 1 provides participants' demographic background related to the gender of the 
respondents, of which a majority (55.6\%) were male and (44.4\%) being female. In relation to grade level, the majority (39\%) of the students reported being $11^{\text {th }}$ graders, followed by $10^{\text {th }}$ graders $(33 \%)$ and $9^{\text {th }}$ graders $(28 \%)$. There were no reported $12^{\text {th }}$ graders. Regarding race and ethnicity, the majority (94\%) self-reported as White, with the remaining 6\% self-reporting as Hispanic.

Students were asked to report the number of days they lived, visited or worked on a farm out of the year. The majority (33.3\%) reported living, visiting or working on a farm 157-365 days out of the year. Approximately $27 \%$ of the students reported not living, visiting or working on a farm. Sixteen percent reported living, visiting or working on a farm for 1-12 days or 13-52 days. None of the students reported living, visiting or working on a farm for 53-110 days.

Table 1: Participant's Demographic Background

\begin{tabular}{|l|l|c|c|}
\hline \multicolumn{1}{|c|}{ Demographic } & \multicolumn{1}{|c|}{ Item } & $f$ & $\%$ \\
\hline Gender & Male & 10 & 55.6 \\
\hline Grade level & Female & 8 & 44.4 \\
\hline & $9^{\text {th }}$ & 5 & 27.8 \\
\hline & $10^{\text {th }}$ & 6 & 33.3 \\
\hline & $11^{\text {th }}$ & 7 & 38.9 \\
\hline Race/Ethnicity & $12^{\text {th }}$ & --- & --- \\
\hline & African American & --- & --- \\
\hline & White & 17 & 94.4 \\
\hline & Hispanic & 1 & 5.6 \\
\hline & Native American & --- & --- \\
\hline & Asian & --- & --- \\
\hline $\begin{array}{l}\text { Number of days in the year you lived, } \\
\text { visited or worked on arm }\end{array}$ & Other & --- & --- \\
\hline & None & 5 & 27.8 \\
\hline & Several, 1-12 days & 3 & 16.7 \\
\hline & Some, 13-52 days & 3 & 16.7 \\
\hline & Most, 53-110 days & --- & --- \\
\hline & $\begin{array}{l}\text { Almost All, 111-156 } \\
\text { days }\end{array}$ & 1 & 5.6 \\
\hline & $\begin{array}{l}\text { Everyday 157-365 } \\
\text { days }\end{array}$ & 6 & 33.3 \\
\hline
\end{tabular}

The researchers conducted analyses of three characteristics in this study:

1-Grade level (9th, 10th or $\left.11^{\text {th }}\right)$; 2-Gender; and 3-Number of days living, visiting or working on a farm (ranging from $0-365$ days). These characteristics were compared to students' responses related to farm safety practices. 
The questionnaire items were presented as 4-point Likert-type scale responses, in which 1=Always, $2=$ Sometimes, $3=$ Never" and $4=$ Not Sure. The respondents' grade level, gender and number of days living, visiting or working on a farm were compared with their responses to the questions about farm safety practices. The selected results follow:

Regarding wearing hearing protection when working with equipment, the results show a majority (53\%) of the students reported they "Sometimes" wear hearing protection. Only the $9^{\text {th }}$ graders reported "Always" $(20 \%)$ wearing hearing protection. With regard to gender, it was almost equally distributed: about 50\% reported as "Sometimes" wearing hearing protection, while a few, $17 \%$ of the females reported "Always" wearing hearing protection. Of the students who lived, visited or worked 157-365 days a year on a farm, 50\% said they "Sometimes" and 50\% said they "Never" wear hearing protection.

When asked while working in direct sunlight, if they wear protective clothing or use sunscreen, a majority (53\%) of the students reported "Sometimes" wearing protective clothing or using sunscreen. Only the $9^{\text {th }}$ graders stated they "Always" $(40 \%)$ wear protective clothing. With regard to gender, the responses were mostly equally distributed among male and female students: about 50\% reported "Sometimes" while 33\% of the females reported "Always" wearing protective clothing or using sunscreen. Of the students who reported living, visiting or working 157-365 days a year on a farm, 17\% reported "Always," 50\% reported "Sometimes" and 33\% reported "Never" wearing protective clothing or using sunscreen when working in direct sunlight.

Regarding pollutants, students were asked to report if they wear some type of breathing mask, the results show forty percent of the students indicated "Sometimes" wearing breathing masks, while 20\% reported "Always" wearing breathing masks, which was distributed equally across the reported grade levels. Most (22\%) of the male students and $17 \%$ of the female students reported "Always" wearing some type of breathing mask when working with pollutants. Of the students who lived, visited or worked 157-365 days a year on a farm, 17\% reported "Always" wearing breathing masks and $67 \%$ said they "Sometimes" wear some type of breathing mask when working with pollutants.

Regarding the wearing of safety eye wear, hard hats or chaps when using a chainsaw, most $(40 \%)$ of the students indicated they "Sometimes" wear safety equipment when using chainsaws and 20\% reported "Always" 
wearing safety equipment, distributed equally across the grades. Approximately 33\% of both male and female students reported "Always" wearing safety equipment when using a chainsaw. Of the students who lived, visited or worked 157-365 days a year on a farm, 17\% selected "Always" and $33 \%$ selected "Sometimes" wearing protective equipment when using a chainsaw. An alarming 50\% of the students reported "Never" wearing protective equipment when using a chainsaw.

When asked if instructions on pesticide containers are read, most $(73 \%)$ of the students reported that they "Always" read instructions on pesticide containers. All of the $9^{\text {th }}$ graders reported "Always" reading instructions, compared to $20 \%$ of the 10 th and $11^{\text {th }}$ graders. All female students reported "Always" reading instructions on pesticide containers, while $55 \%$ of the males said they "Always" read instructions. Of the students who lived, visited or worked 157-365 days a year on a farm, a significant (83\%) reported "Always" reading instruction on pesticide containers.

Regarding the storing of pesticides in original, labeled containers, a majority (60\%) of the students reported "Always" storing pesticides in original, labeled containers. while $80 \%$ of the $9^{\text {th }}$ and $11^{\text {th }}$ graders reported "Always" storing pesticides in original, labeled containers. Approximately $67 \%$ of female students and $56 \%$ of male students said they "Always" store pesticides in original, labeled containers. As assumed from previous students' responses of those who lived, visited or worked 157-365 days a year on a farm, a significant $83 \%$ reported "Always" storing pesticides in original, labeled containers.

When asked to report if they observe safety warnings for farm machinery, only $40 \%$ of students reported "Always" and another $40 \%$ reported "Sometimes" observing safety warnings on farm machinery, while $13 \%$ reported "Never" observing safety warnings. A majority (67\%) of the female students said they "Always" observe safety warnings, while 56\% of the males selected "Always." Of the students who lived, visited or worked 157-365 days a year on a farm, 50\% selected "Always" and another 50\% selected "Sometimes" in describing how often they observe safety warnings on farm machinery.

\section{Conclusion}

This study is important due to injuries being the leading cause of death for adolescents in the United States (Westaby \& Lee, 2003); this study's results imply that students often put themselves at risk while working on farms. The researchers determined, based on the results, that while some 
students were slightly knowledgeable about and practiced safe farming practices, many were not. This could possibly be attributed to the respondents' age, gender, lack of experience or lack of training. Similar studies have been conducted, and their findings support this study's results that the amount of training provided for youth is directly related to presenting possible injury (Knight, Castillo, \& Layne, 1995; Westaby \& Lee, 2003). Of the experienced students who reported living, visiting or working 157-365 days a year on a farm, a significant 83\% reported "Always" storing pesticides in original, labeled containers; $83 \%$ also reported that they "Always" read instructions on pesticide containers which was reported as well from a majority across grade levels. Only half of the experienced students living, visiting or working 157365 days a year on a farm observed safety warnings on farm machinery. An alarming 50\% said they "Never" wear protective equipment when using a chainsaw, and 50\% reported "Never" wearing hearing protection when working with farm equipment. This study's results align with similar studies that suggest very few youth working on farms receive adequate training for working with hazardous materials or know about the potential risks (Arcury, Rodriquez, Kearney, Arcury, \& Quandt, 2014; Westaby \& Lee, 2003).

Farm safety concerns among youth is further demonstrated by-another area of concern such as machine use safety; only $40 \%$ of the students reported "Never" removing shields on machinery and 30\% reported "Sometimes" removing shields; only 40\% "Always" observed safety warnings on machinery, and 30\% reported "Sometimes" observing these same warnings. Fifty percent reported "Never" wearing hearing protection and 33\% reported "Never" wearing protective clothing or using sunscreen when working in direct sunlight.

A majority of the students fail to read pesticide instructions or store pesticides in original containers. Additional results found that the number of tractors on student farms was significantly low, with only $18 \%$ of the tractors being equipped with ROPS. However, there was a higher rate of students, $73 \%$, who allow extra riders on machinery. This could be a result of poor or no training received prior to machine operation or risk-taking (McCurdy \& Kwan, 2012).

To address this issue, The U.S. Department of Labor has proposed provisions that would require 14 and 15-year-olds to operate only tractors that have ROPS and seatbelts, and to receive additional safety training before use. Furthermore, $27 \%$ of the students reported never using any type of protection from the sun and 33\% said they never use hearing protection. As it relates to using safety materials when using chainsaws, only $1 / 3$ of the students reported "Always" using protective equipment when using chainsaws. In this study, a majority of participants were male, which is significant as findings from similar studies conducted by other researchers (Rivara, 1997; Stueland, Layde, 
\& Lee, 1991; Westaby \& Lee; 2003; Zietlow \& Swanson, 1999), reported that males have higher occurrences of farming injuries.

\section{Recommendations for Future Studies}

Based on the conclusions, the researchers recommend that future studies be conducted to determine if participants' race/ethnicity, age level, and farming experience after receiving farm safety initiatives such as farm demonstrations, will reduce the potential for experiencing hazards on their farms. This information is vital; even with children being at high risk for agricultural injury, there is little documentation about the range of farm work they perform or the ages at which they experience these work exposures (Marlenga, Pickett, \& Berg 2001). The researchers hope to seek funding to conduct more farm safety audits; develop training materials; and develop social media outlets to train Cooperative Extension educators, high school teachers and rural youth program staff in ways to educate rural youth about safe farming practices. It is also recommended that The Cooperative Extension Program offer events such as The Farm Safety Field Day for more rural youth as well as adult farmers, farm workers, and migrant workers.

\section{References:}

1. Arcury, T., Rodriquez, G., Kearney, G., Arcury, J., \& Quandt, S. (2014). Safety and injury characteristics of youth farmworkers in North Carolina: A pilot study, Journal of Agromedicine, 19(4), 354363.

2. Hard, D.L., \& Myers, J.R. (2008). Fatal work-related injuries in the Agriculture production sector among youth in the United States, 19922002. Journal of Agromedicine, 11(2), 57-65

3. Knight, E., Castillo, D., \& Layne, L. (1995). A detailed analysis of work-related injury among youth treated in emergency departments. American Journal of Industrial Medicine, 27(6), 793-805, Available at: https://doi.org/10.1002/ajim.4700270604

4. McCurdy, S., \& Kwan, J. (2012). Ethnic and gender differences in farm tasks and safety practices among rural California farm youth. Journal of Occupational and Environmental Hygiene, 9(6), 362-370.

5. Marlenga, B, Pickett, W., \& Berg, L. (2001). Agricultural work activities reported for children and youth on 498 North American farms. Journal of Agricultural Safety and Health, 7(4): 241-252, DOI: $10.13031 / 2013.6221)$

6. NIOSH. (2014). Agricultural Safety. Retrieved from: https://www.cdc.gov/niosh/topics/aginjury/

7. OSHA. (2014). Agricultural Operations: Youth in Agriculture. Retrieved from: 
https://www.osha.gov/dsg/topics/agriculturaloperations/youngworker s.html

8. Rivara, F. (1997). Fatal and non-fatal farm injuries to children and adolescents in the United States, 1990-1993. Injury Prevention, 3, 190-194.

9. Stueland, D., P.M., Layde, \& Lee, B.C. (1991). Agricultural injuries in children in Central Wisconsin, 3. 1503-1509.

10. USDA. (2012). Agricultural safety: 2009 injuries to youth on farms. Retrieved from: http://www.nass.usda.gov/

11. USDA, National Agricultural Statistics Service. (2017). 2017 Census of Agriculture - State Data

North Carolina 43. Retrieved from: http://www.nass.usda.gov/.

12. Westaby, B., \& Lee, J. (2013). Antecedents of injury among youth in agricultural settings: A longitudinal examination of safety consciousness, dangerous risk taking, and safety knowledge. Journal of Safety Research, 34(3), 227-240.

13. Zietlow, S. P, \& Swanson, J. (1999). Childhood farm injuries.

The American Surgeon, 65(7), 693-697. 